\title{
O princípio da autoconfrontação na abordagem da Clínica da Atividade
}

\author{
Marcello Santos Rezende, ${ }^{\text {Orcid, I, } \star \star}$ Cirlene de Souza Christo ${ }^{\text {Orcid, II }}$ \\ ${ }^{I}$ Fundação Oswaldo Cruz, Rio de Janeiro, RJ, Brasil \\ ${ }^{I I}$ Universidade Federal do Rio de Janeiro, Rio de Janeiro, RJ, Brasil
}

\begin{abstract}
RESUMO
Na busca por instrumentos teórico-metodológicos compatíveis com a adoção do ponto de vista da atividade em pesquisa e intervenção no trabalho, discute-se o princípio da autoconfrontação como método indireto na abordagem da Clínica da Atividade visando a favorecer o desenvolvimento do poder de agir dos sujeitos e coletivos sobre si e sobre o meio de trabalho. Ressaltam-se as potencialidades do método em propiciar uma experiência formadora e impulsionar o desenvolvimento dos sujeitos em termos de ampliação de sua capacidade de agir, assim como o limite em relação à proposta de transformação das situações de trabalho.
\end{abstract}

Palavras-chave: autoconfrontação; métodos em Psicologia do Trabalho; Clínica da Atividade.

\section{The Principle of Self-Confrontation in Clinic of Activity Approach}

\begin{abstract}
In the search for theoretical and methodological tools compatible with the adoption of the activity point of view in research and intervention, the principle of self-confrontation is discussed as an indirect method in Clinic of Activity approach aiming to favor the development of the power to act of the individual and collectives on themselves and their work environment. The potential of the method is emphasized in providing a formative experience and boosting the workers development in terms of their capacity to act, as well as the limit in terms of the transformation of work situations.
\end{abstract}

Keywords: self-confrontation; methods in Work Psychology; Clinic of Activity.

\section{Introdução}

Estudar e intervir no trabalho não pode prescindir de considerar a sua complexidade, o que impede que se pretenda isolar esse objeto da situação concreta, do contexto e das dimensões históricas, sociais e subjetivas presentes nos meios e processos de trabalho. Com base nessa premissa, tem-se buscado no conceito transversal de atividade um ponto de vista que possibilite a articulação entre os saberes de diferentes disciplinas e abordagens pertinentes ao campo do trabalho, bem como entre esses e os saberes produzidos nas experiências das pessoas que trabalham.

$\mathrm{Na}$ proposta pluridisciplinar da Ergonomia da Atividade, o constructo atividade tem sido amplamente utilizado para designar aquilo que é especificamente humano no trabalho (BÉGUIN, 2006). De acordo com essa tradição, o trabalho nunca é pura execução. Ele se desdobra em inúmeras experiências e situações singulares e concretas, marcadas pela variabilidade e imprevisibilidade dos estados do processo e dos operadores humanos, frente às quais as prescrições são sempre insuficientes (DANIELLOU; LAVILLE; TEIGER, 1989). Insuficientes especialmente porque elas se apresentam como normas estabelecidas em experiências de duração diferente e com trabalhadores distintos daqueles que delas fariam uso nas situações específicas de trabalho.

É em função da constatação de que há essa distância permanente entre o que denominaram "trabalho prescrito" e "trabalho real" que os ergonomistas procuram

^ O presente trabalho foi realizado com o apoio da Coordenação de Aperfeiçoamento de Pessoal de Nível Superior (CAPES), da Fundação Carlos Chagas Filho de Amparo à Pesquisa do Estado do Rio de Janeiro (FAPERJ) e do Conselho Nacional de Desenvolvimento Científico e Tecnológico (CNPq) - Brasil. $\star \star$ Endereço para correspondência: Fundação Oswaldo Cruz, Presidência da Fiocruz, Coordenação de Saúde do Trabalhador. Av. Brasil, 4365 - Pavilhão Carlos Augusto da Silva, Sala 114. Manguinhos - Rio de Janeiro, RJ - Brasil. CEP: 21040360.E-mail: marcellosantosr@gmail.com, cirlenechr@gmail.com colocar em evidência o trabalho que se faz efetivamente, tendo em conta as exigências e constrangimentos na confrontação de cada pessoa, singular e variável, com situações também singulares e variáveis. Como trabalho prescrito, referem-se ao conjunto de objetivos a serem perseguidos, os métodos, as normas técnicas, os protocolos e procedimentos, as ordens e instruções a seguir, a forma de divisão do trabalho, os prazos estabelecidos, assim como os meios técnicos e as condições socioeconômicas disponíveis (GUÉRIN et al., 2005). Como trabalho real, referem-se à adaptação do prescrito às situações reais de trabalho (BRITO, 2006), isto é, àquilo que se mobiliza do sujeito para que o trabalho seja realizado frente às situações reais, caracterizadas por seu dinamismo, instabilidade e imprevisibilidade. A atividade (de trabalho) é reconhecida como o que torna possível compreender a natureza dos problemas da forma como são vividos pelos trabalhadores e não apenas por uma visão externa.

Nessa linhagem propõe-se uma modalidade de pesquisa-intervenção como coprodução dos profissionais de pesquisa e os do trabalho em questão, que articula a compreensão do existente com a ação sobre o futuro, contribuindo para a definição de uma situação de trabalho mais favorável (GUÉRIN et al., 2005). Essa modalidade caracteriza-se pela busca de dar visibilidade tanto às dificuldades quanto às táticas e estratégias desenvolvidas pelos protagonistas do trabalho para gerir a distância entre o prescrito e o real, engendrando-se as atividades de trabalho. No plano metodológico, desenvolve-se o método da Análise Ergonômica do Trabalho (AET), no interior do qual se situa a análise psicológica do trabalho, cujos começos na França e Bélgica - de Pacaud a Faverge forneceram bases para o desenvolvimento dessa tradição. 
Encontra-se hoje um importante esforço de atribuir maior rigor à noção de atividade, buscando dar a ela um estatuto de conceito, sem abandonar o enfrentamento de sua complexidade e seu caráter sempre enigmático (SCHWARTZ, 2007; ATHAYDE; REZENDE, 2015). Essa noção vem sendo incorporada como conceito-chave em diferentes abordagens e perspectivas teórico-metodológicas, em algum grau herdeiras da tradição da Ergonomia da Atividade, que também têm como projeto compreender $\leftrightarrow$ transformar o trabalho. Dentre elas, a Clínica da Atividade (CLOT, 2006), a Psicodinâmica do Trabalho (DEJOURS, 1997) e a Ergologia (SCHWARTZ; DURRIVE, 2010). Neste texto discutiremos o princípio da autoconfrontação em uma abordagem clínica de análise do trabalho e das atividades humanas, especialmente como vem sendo utilizado na abordagem da Clínica da Atividade, através das contribuições presentes em textos de Yves Clot e Daniel Faïta (2000; CLOT, LEPLAT, 2005; FAÏTA; MAGGI, 2007).

\section{Abordagem da Clínica da Atividade}

A Clínica da Atividade valoriza a ação dos coletivos e a transformação das situações de trabalho. Destacando a relevância da função psicológica do trabalho, essa abordagem explora as condições de "ampliação do poder de agir dos coletivos de trabalhadores no meio de trabalho e sobre eles próprios" (CLOT, 2001, p. 9), tendo como via privilegiada de transformação do trabalho o desenvolvimento de recursos para a ação que compõem o patrimônio coletivo dessas experiências.

A partir do reconhecimento de uma não linearidade do processo de desenvolvimento humano e da possibilidade do homem de transformar sua realidade e história, de criar novas condições para sua própria existência, Faïta e Clot ressaltam em contexto de pesquisa e intervenção no trabalho a importância da relação destacada por Vigotski entre pensamento e linguagem. Para Vigotski (1934/2001), assim como o trabalho, que mediado por instrumentos permite ao homem transformar a natureza, as funções psicológicas superiores são mediadas por sistemas de signos, os quais atuam como instrumentos psicológicos. Esses signos-instrumentos (especialmente a linguagem verbal), apesar de não serem capazes de modificar o objeto da operação psicológica, se dirigem para o controle e transformação do próprio indivíduo, de seu psiquismo, de seu comportamento.

É nesse sentido que para Faïta (2005, p. 19), no âmbito da perspectiva ergológica e da abordagem da Clínica da Atividade, "falar do trabalho, implica em trabalhar a fala". Para ele, a linguagem, além de ser a única a autorizar a capitalização de nossas experiências, é quem permite agir sobre o outro e sobre nós mesmos.

$\mathrm{O}$ trabalho de reflexão e de formalização permite à pessoa tomar consciência de seu potencial, da maneira como se investe em sua atividade. Do mesmo modo, permite também descobrir e eventualmente modificar a relação que ele estabelece com o objeto de sua própria atividade e de seus modos operatórios (FAÏTA, 2010, p. 178).
Dessa forma, na abordagem da Clínica da Atividade, a proposta de colocar a experiência em palavras não tem como propósito seu desvelamento, mas o de compreender melhor o que se faz e, reconhecendo a complexidade da atividade, reformulá-la. Destacando a relevância da função psicológica do trabalho, a atividade de linguagem sobre a atividade de trabalho é considerada um recurso de desenvolvimento para o protagonista da atividade, assim como de evolução em suas relações como coletivo e, quiçá, de transformação de seu contexto. Isto pela revitalização do gênero profissional que pode se seguir da renovação dos estilos individuais da ação.

\section{Gênero profissional e estilos individuais da ação}

Para Clot e Faïta (2000) não há uma polarização entre a prescrição e a atividade como dois lados opostos. Entre a organização do trabalho e o próprio sujeito se configuraria um trabalho de (re)organização efetuado pelos coletivos profissionais. Trabalho este que, tomando emprestado de Bakhtin o conceito de gênero do discurso, denominam "gênero profissional". Esse conceito ajuda a compreender que além da tarefa prescrita oficial há outro nível de prescrição: um referencial estabelecido em comum de normas da profissão e regras não escritas em uma situação profissional que, validadas por um coletivo de trabalho, "definem não somente a maneira como os membros do coletivo devem se comportar nas relações sociais, mas também os modos de trabalhar aceitáveis" (CLOT; FAÏTA, 2000, p. 13, tradução nossa), fornecendo bases para a gestão efetuada pelos sujeitos na atividade entre motivos pessoais, cumprimento da tarefa e relacionamento com colegas. Os coletivos de trabalho mobilizam o gênero profissional como um mediador entre a tarefa prescrita e a atividade. Nesse sentido, o gênero assume uma função psicológica importante, pois além de colaborar do ponto de vista organizacional, vai também representar um recurso para a própria ação de cada trabalhador.

Todavia, segundo CLOT (1999), a vitalidade do gênero profissional depende da função criadora dos "estilos individuais da ação", isto é, de um modo singular do sujeito tomar a memória coletiva do gênero, ajustando-a às exigências de cada situação de trabalho. Tal processo psicológico permitiria ao sujeito ajustar também o gênero, mantendo-o vivo, desenvolvendo-o. Em suma, os estilos podem tornar-se uma apropriação psicológica eficaz e um fator de desenvolvimento caso eles sejam submetidos ao corpo de avaliações comuns que constituem o gênero profissional. Em contrapartida, quanto mais forte for este, maior a capacidade de estilização da pessoa ou do coletivo e sua possibilidade de correr riscos e trabalhar de novos modos, abrindo outros possíveis para a atividade.

Como anteriormente indicado, no plano metodológico, a abordagem da Clínica da Atividade visa a instalar no seio dos coletivos debates em que o gênero profissional recupere as suas qualidades, explorando as condições de ampliação do "poder de agir" dos coletivos de trabalhadores no meio de trabalho e sobre eles próprios. Aos psicólogos do trabalho cabe, em um processo de coanáli- 
se com os protagonistas das atividades, a tarefa de contribuir com um coletivo para a (re)construção, revitalização do gênero profissional.

\section{A autoconfrontação como um método indireto}

Com base na proposição de Vigotski de que "o comportamento é apenas um sistema de reações que venceram" (VIGOTSKI, 1927/1999, p. 67) dentre as diferentes ações possíveis em determinada situação, Clot (2010) enfatiza que o conceito de atividade de trabalho deve englobar, além das atividades de trabalho realizadas, aquilo "que não se faz, o que não podemos fazer, o que procuramos fazer sem conseguir - os fracassos -, o que gostaríamos ou poderíamos fazer, o que pensamos ou sonhamos poder fazer" (CLOT, 2006, p. 116), ao que denomina "real da atividade". Propõe, assim, que a experimentação em análise/clínica da atividade se oriente também para a investigação dos movimentos internos não realizados, os quais, por esta ótica, são tão reais quanto os que se realizaram. Todavia, não sendo as possibilidades descartadas da atividade acessíveis por observação direta, Clot sugere, conforme Vigotski, que se usem métodos indiretos de análise, especialmente os que fazem uso do princípio metodológico da autoconfrontação.

Originário da Ergonomia (PINSKI; THEUREAU, 1982) e explorado por Pélegrin (2011), Faïta (FAÏTA; MAGGI, 2007) e Clot (2006, 2010), a autoconfrontação tem sido tomada por diversos profissionais de pesquisa-intervenção para delinear meios e espaços favoráveis a que se manifestem os conflitos vitais da atividade de trabalho (CLOT; LEPLAT, 2005; FAÏTA; MAGGI, 2007), inacessíveis por meio de observações diretas. Em uma de suas formas, consiste em um encontro entre a atividade de trabalho de um agente e ele mesmo, com o propósito de deflagração de um novo contexto no qual o sujeito se torna um observador de sua própria atividade. Segundo Faïta (FAÏTA; MAGGI, 2007), esse novo contexto é construído por meio da troca verbal dos sujeitos, tanto com o objeto de seu trabalho quanto com seus interlocutores presentes ou não no momento em que essa nova atividade se dá.

O ponto de partida dessa proposta metodológica está no deslocamento do plano da observação. À diferença de modelos tradicionais, destaca-se e tiram-se consequências do que, a partir de Henry Wallon, se denomina "estatuto psicológico da observação na investigação" (CLOT; LEPLAT, 2005, p. 302). O pressuposto é o de que toda observação do trabalho do outro implica em uma ação sobre esse que é observado, isto é, produz no mesmo uma atividade de observação sobre si. Dessa forma, no curso de uma atividade, a observação da atividade de alguém incita nessa pessoa uma atividade interior específica (um diálogo interior, uma reflexão sobre sua própria ação), que pode lhe fornecer uma via de desenvolvimento, especialmente se forem criadas condições para que seja dado a esse diálogo interior um destino dialógico no plano intersubjetivo. Como já dito, não como via de escuta da experiência com fins de desvelá-la, mas para conhecê-la em seu desenvolvimento possível.

Fractal, Rev. Psicol., v. 30 - n. 2, p. 131-136, 2018
Acompanhando Vigotski (1925/1998; 1927/1999) também na indicação de que o objeto do conhecimento não deve ser considerado em seu produto, mas em seu processo de mudança, Clot (CLOT; LEPLAT, 2005) indica que não se trata apenas de compreender a atividade para transformá-la - como sugere ser o proposto em Ergonomia da Atividade - mas igualmente de transformá-la para compreendê-la. Essa situação em que os sujeitos do trabalho se tornam os observadores e intérpretes de sua própria atividade, segundo ele, cria condições para que a atividade cotidiana se torne um meio do pensamento coletivo. Dessa maneira, a análise do trabalho pelo pesquisador não seria diretamente o recurso da ação, mas um recurso para secundar uma experiência de análise e modificação do trabalho por aqueles que o protagonizam. Nesse sentido, a proposta é por um processo de coanálise do trabalho, na qual os protagonistas das atividades de trabalho se engajam nas atividades de observação e análise de suas atividades de trabalho, dando-se ênfase à atividade linguageira verbal que incide sobre as mesmas. Nesse processo, a verbalização se configura não apenas como um meio de ter acesso às atividades de trabalho, mas como uma nova atividade do sujeito. Nele a ação de mediação do pesquisador é decisiva. Colocando-se como o organizador da situação de análise e, ao mesmo tempo, como um de seus personagens, ajuda os sujeitos a construírem uma representação linguageira e simbólica (FAÏTA; MAGGI, 2007) de sua atividade. Reconhecendo que a transparência da atividade é uma ilusão, mesmo nessas atividades linguageiras, Clot e Faïta recorrem a uma abordagem dialógica da situação, tendo em Bakhtin (2010) uma importante referência.

Enquanto método (ou técnica com base no princípio de autoconfrontação) utilizado pela abordagem da Clínica da Atividade, a autoconfrontação consiste em submeter ao exame de um trabalhador a imagem (normalmente em vídeo) de seu próprio trabalho, em forma de sequências, solicitando-lhe expressar em palavras (comentário) sua própria atividade (FAÏTA, 2010). ${ }^{1}$ Nesse tipo de experimentação, a partir dos comentários que destina ao observador, o sujeito projeta sobre sua atividade passada um olhar que o transforma em interlocutor atual daquilo que ele fez no momento da ação (FAÏTA; MAGGI, 2007). Costuma-se referir a esse encaminhamento como uma autoconfrontação simples para distinguir de outro, normalmente realizado a posteriori, ao qual denominam autoconfrontação cruzada (CLOT, 2010), em que o olhar questionador do(s) par(es) de trabalho é incluído como forma de contribuir para reacender ou revelar ressonâncias, correlações e contradições nessa nova atividade do sujeito de análise de sua atividade de trabalho.

O esquema, nessas circunstâncias, é quase sistemático. Confrontado ao espetáculo de seu trabalho, o ator passa por graus na apreciação de sua própria atividade. Os componentes de sua ação o conduzem a dar inicialmente uma imagem de como ele vê a si mesmo. Depois abandona essa

${ }^{1} \mathrm{O}$ autor chama a atenção para a questão ética do método, advertindo que a autoconfrontação só poderá ser realizada depois de uma séria negociação com os sujeitos, assegurando que os mesmos compreenderam as implicações de se submeterem ao exercício. 
imagem para entrar no estágio de colocar em palavras aquilo que caracteriza a especificidade de sua ação, o que se atrela, em última instância, a outras constantes que são as do coletivo no qual ele se reconhece (FAÏTA, 2010, p. 183).

De uma posição deslocada ao olhar seu trabalho, e face às escolhas ou dilemas que redescobre em sua atividade, aquilo que estava como resposta automática torna-se questão para o sujeito (CLOT; LEPLAT, 2005). De objeto, a atividade de trabalho, revivida em uma situação transformada, se torna meio. Assim, apesar de não se negar a importância dos conteúdos do trabalho, Faïta (FAÏTA; MAGGI, 2007, p. 26) adverte que "este método não é um processo de coleta de dados e menos ainda um meio de fazer dizer o que as pessoas não têm como entender", mas um dispositivo que visa à instauração de um conjunto de redes dialógicas, de atividades linguageiras sobre a atividade de trabalho, de forma a iniciar uma reconstrução do sujeito à sua ação passada, abrindo os possíveis à sua atividade futura.

Os registros em vídeo, nas autoconfrontações cruzadas, têm sido os mais investidos nos estudos franceses atuais. No Brasil também há estudos que fazem uso do vídeo (SANTORUM et al., 2008), no entanto o recurso da fotografia tem sido mais explorado como dispositivo da intervenção em Clínica da Atividade, sobretudo nos grupos de pesquisa NUTRAS/UFF (SILVA; SOUTO; MEMÓRIA-LIMA, 2015) e NEPESP/UFES (ROSEMBERG; RONCHI FILHO; BARROS, 2011).

\section{A técnica Instruções ao Sósia}

A técnica denominada Instruções ao Sósia foi desenvolvida por Oddone, Re e Briante (1981), dentro de uma proposta de análise-intervenção, conhecida no Brasil como Modelo Operário Italiano (MOI) de produção de conhecimento e luta pela saúde. Foram esses autores quem introduziram a ideia de uma Comunidade Científica Ampliada (CCA), privilegiando a confrontação entre os saberes formais dos pesquisadores e os saberes informais dos trabalhadores na busca de novos critérios que permitam definir os índices de nocividade do trabalho e novas formas de participação operária.

Usada em contextos de seminários de pesquisa-formação (portanto em grupo), essa técnica era usada com o propósito de levar os trabalhadores participantes "a traduzir no plano de comportamentos reais as imagens da fábrica e dos homens que são ligados à sua experiência pessoal e à sua visão de mundo" (ODDONE; RE, BRIANTE, 1981, p. 57, tradução livre). O protocolo consistia em pedir que cada sujeito fornecesse instruções a um sósia imaginário (o pesquisador), a partir da formulação da seguinte solicitação:

Se houvesse outra pessoa perfeitamente idêntica a você do ponto de vista físico, como lhe diria para se comportar na fábrica em relação à sua tarefa, aos seus colegas de trabalho, à hierarquia e à organização sindical (ou outras organizações de trabalhadores), de modo que não se percebesse que é outro que não você? (ODDONE; RE, BRIANTE, 1981, p. 57, tradução livre).
Tal como fora posteriormente proposto no que se convencionou chamar método de autoconfrontação (CLOT; LEPLAT, 2005; FAÏTA; MAGGI, 2007), o objetivo não era apenas a formalização da experiência informal de modo que ela pudesse ser transmissível, mas também seu enriquecimento e renovação. Dar instruções a um sósia, para Oddone, Re e Briante (1981), significa reestruturar e ordenar os comportamentos particulares em um plano global, desenvolvendo a experiência dos trabalhadores. Da interação entre dois sujeitos ou grupos, produz-se, segundo eles, uma tomada de consciência, num processo dialético entre pessoas reais que permite, não apenas identificar os planos dos trabalhadores (no sentido cognitivo), como também enriquecê-los. Os autores advertem que esse processo de enriquecimento nunca poderá ser concluído e que essa experiência nunca será totalmente apreendida. No que se refere à questão desse texto, é justamente porque o retorno da experiência não é realizado sobre a atividade de trabalho, mas sobre a experiência de sua transmissão (uma atividade de linguagem), que se pode classificar a técnica Instruções ao Sósia como uma forma de operar um método indireto de análise da atividade.

A partir de um quadro específico de análise, Clot (2006) e colaboradores buscaram compreender os recursos psicológicos que dão sustentação a essa técnica, propondo alguns avanços nos planos metodológico e procedimental. Nos projetos de pesquisa realizados pelo grupo que esse autor faz parte a autoconfrontação se realiza em dois tempos: (1) durante a instrução, pela mediação da atividade do sósia; e (2) após a mesma, quando os materiais coletados são retomados pelo sujeito, que é solicitado a comentá-los por escrito. O autor chama atenção de que é em função da impossibilidade de uma substituição efetiva que o trabalhador que instrui reencontra as hesitações e alternativas de suas escolhas, facilitando o contato social do sujeito consigo mesmo mediante o deslocamento de suas atividades a um novo contexto. Explica que aquele posicionado como sósia, explorando a situação que antecipa como uma fonte para sua ação futura, busca todas as possibilidades e obstáculos que esta pode oferecer. Sua atividade, na medida em que reclama esses meios para agir na situação por si projetada, obriga o sujeito a se desprender de seus esquemas de ação usuais, recolocando-o frente às escolhas que fez, assim como às contradições que comportam essas escolhas. Em conformidade com o princípio metodológico da autoconfrontação, o sósia busca acessar o que compõe não apenas a ação vivida, mas também a não vivida (isto é, o real da atividade). Sua indeterminação acaba por operar uma ruptura no encadeamento habitual das operações do sujeito, o que pode contribuir para o processo de subjetivação. De outro lado, para que não seja reconhecido, o sósia busca uma conformidade operatória às instruções do outro e isto abre a possibilidade do sujeito experimentar essa busca como uma redução das possibilidades de sua atividade, levando-o a refletir não somente sobre o "como" (insistentemente reclamado pelo sósia), mas também sobre o "porquê" de sua ação. 
A autoconfrontação do sujeito com traços materializados (transcrições das gravações de áudio da instrução) da troca verbal realizada na situação de instrução, somada à exigência de troca verbal escrita com outros, produz um diálogo consigo mesmo (SILVA, 2014) que pode ter um destino desenvolvimental para o sujeito do trabalho em análise, individual e coletivamente.

\section{Potencialidades e limites da autoconfrontação na Clínica da Atividade}

Ressalta-se o lugar ativo em que a abordagem da Clínica da Atividade situa os protagonistas do trabalho na análise da atividade e das situações de trabalho. Lugar esse, distinto de uma posição de informantes como não é incomum em abordagens clássicas da Psicologia do Trabalho. Todavia, algumas questões se colocam aos projetos de pesquisa-intervenção que se orientam por essa abordagem no que se refere aos propósitos de ampliação do poder de agir dos coletivos. Em uma intervenção clínica, a ação de mediação do pesquisador, baseada no princípio metodológico de autoconfrontação, tem como objetivo que os trabalhadores, individual e coletivamente, possam desenvolver recursos para a ação, contribuindo para a revitalização do gênero profissional e a transformação do trabalho. É sobre esse último aspecto que se coloca a questão dos limites e potencialidades dessa abordagem na transformação das situações de trabalho, para além da transformação dos sujeitos.

Reconhece-se a originalidade de Clot $(2006,2010)$ ao relacionar diretamente desenvolvimento individual, fortalecimento do gênero profissional e transformação das situações de trabalho. No entanto, aponta-se para o risco de misturar e confundir diferentes fenômenos ao unificá-los todos sob a expressão "desenvolvimento do poder de agir" (CLOT, 2010). Uma situação de coanálise pode propiciar uma experiência formadora e impulsionar o desenvolvimento dos sujeitos em termos de ampliação de sua capacidade de agir. Todavia, conforme Rabardel e Gouédard (2012), entende-se que a noção poder de agir envolve, além de recursos individuais e coletivos - como a possibilidade do uso ampliado dos instrumentos e a capacidade de utilização de regras de ação mais complexas -, aquilo que concretamente é possível fazer, dadas as características singulares das situações de trabalho. Por essa ótica, só se poderia dizer que há ampliação do poder de agir se os resultados de uma intervenção ganhassem sustentação no curso da atividade de trabalho, isto é, se fosse possível mudar a situação de trabalho de forma que os trabalhadores pudessem exercer uma maior autonomia sobre aquilo que é importante para eles e para o coletivo do qual fazem parte.

Nessa linha de discussão, cabe fazer referência a uma pesquisa-intervenção (CHRISTO, 2013) com supervisores de equipes de produção em uma indústria de pneumáticos. Como metodologia, em um enquadramento clínico orientado pelo referencial da Clínica da Atividade, foi colocado em ação um dispositivo de autoconfrontação, inspirado na técnica Instrução ao Sósia. Os resultados indicaram que os profissionais de supervisão, pela análise que fizeram de suas atividades de trabalho, tiveram oportunidade de reelaborar algumas de suas decisões e escolhas nas atividades de trabalho, assim como ressignificar alguns elementos de seu trabalho, possibilitando-lhes vislumbrar outros possíveis de ação nas situações e contexto de trabalho. Pode-se afirmar que houve indícios de desenvolvimento dos sujeitos. Entretanto, o mesmo não se pode dizer sobre as transformações concretas das situações de trabalho. Constatação que remete a alguns elementos de contextos da experimentação do dispositivo que teve por base esse referencial teórico-metodológico. Um deles refere-se à construção do contrato da pesquisa-intervenção com os dirigentes da empresa, o qual foi caracterizado por uma limitada autonomia na priorização das ações em relação ao objetivo de transformação das situações de trabalho, o que poderia ter sido fomentado se tivesse sido possível uma discussão mais ampliada em outros níveis hierárquicos e instâncias da empresa.

Os resultados contribuem para a afirmação de que a ampliação do poder de agir dos coletivos de trabalhadores na transformação do meio de trabalho não é garantida a priori. Conforme assinalam Teiger e Lacomblez (2006), é necessário que a pesquisa-intervenção trabalhe em dois planos: o do desenvolvimento individual e coletivo dos trabalhadores e o do reconhecimento, na empresa, do sentido e do porte da experiência construída. Para tal, deve-se buscar construir dispositivos-suporte às transformações necessárias. Isto porque a ancoragem das mesmas depende não apenas dos recursos desenvolvidos pelos sujeitos, mas também das condições externas que se reúnem em um dado momento e espaço.

\section{Referências}

ATHAYDE, M.; REZENDE, M. S. Atividade. In: BENDASSOLI, P. F.; BORGES-ANDRADE, J. E. (Org.). Dicionário de psicologia organizacional e do trabalho. São Paulo: Casa do Psicólogo, 2015. p. 101-108.

BAKHTIN, M. Estética da criação verbal. São Paulo: Martins Fontes, 2010.

BÉGUIN, P. Arqueología del conocimiento: acerca de la evolución del concepto de actividad. Laboreal, Paris, v. 2, n. 1, p. 55-61, 2006. Disponível em: <http://laboreal.up.pt/files/ articles/2006_07/es/55-61es.pdf>. Acesso em: 30 out. 2016.

BRITO. J. C. Trabalho prescrito e trabalho real. In: PEREIRA, I. B.; LIMA, J. C. F. (Org.). Dicionário da educação profissional em saúde. Rio de Janeiro: FIOCRUZ, 2006. p. 288-294.

CHRISTO, C. Análise da atividade de supervisão do trabalho: um olhar psico-social para o gerenciamento na indústria. 2013. Tese (Doutorado)-Universidade do Estado do Rio de Janeiro, Rio de Janeiro, 2013.

CLOT Y. Ivar Oddone: les instruments de l'action. Les territoires du travail, n. 3, p. 43-52, 1999.

CLOT Y. Editorial. Education Permanente, v. 146, n. 1, p. 7-16, 2001.

CLOT, Y. A função psicológica do trabalho. Petrópolis, RJ: Vozes, 2006.

CLOT, Y. Trabalho e poder de agir. Belo Horizonte: Fabrefactum, 2010. 
CLOT, Y.; FAÏTA, D. Genres et styles en analyse du travail: concepts et méthodes. Travailler, n. 4, p. 7-42, 2000. Disponível em: <http://psychanalyse.cnam.fr/medias/fichier/ texteclot4_1306851012723.pdf>. Acesso em: 12 set. 2010.

CLOT, Y.; LEPLAT, J. La méthode clinique en ergonomie et en psychologie du travail. Le Travail Humain, v. 68, n. 4, p. 289-316, 2005.

DANIELlOU, F.; LAVILlE, A.; TEIGER, C. Ficção e realidade do trabalho operário. Revista Brasileira de Saúde Ocupacional, São Paulo, v. 17, n. 68, p. 7-13, 1989.

DEJOURS, C. O fator humano. Rio de Janeiro: FGV, 1997.

FAÏTA, D. Análise dialógica da atividade profissional. Rio de Janeiro: Imprinta Express, 2005.

FAÏTA, D.; MAGGI, B. (Org.). Un débat en analyse du travail: deux méthodes em synergie dans l'étude d'une situation d'enseignement. Toulouse: Octarès, 2007.

FAÏTA, D. A linguagem como atividade. In: SCHWARTZ, Y.; DURRIVE, L. (Org.). Trabalho \& Ergologia: conversas sobre a atividade humana. Niterói: EDUFF, 2010. p. 165-186.

GUÉRIN, F. et al. Compreender o trabalho para transformá-lo: a prática da ergonomia. 2. ed. São Paulo: Edgard Blücher, 2005.

ODDONE, I.; RE, A.; BRIANTE, G. Redécouvrir l'expérience ouvrière: vers une autre psychologie du travail? Paris: Messidor, 1981.

PÉLEGRIN, B. Sur l'autoconfrontation: vous avez dit « croisé »? Ergologia, n. 5, p. 107-145, 2011.

PINSKY L.; THEUREAU J. Activité cognitive et action dans le travail: éléments et événements du travail infirmier. Paris: CNAM, 1982. Collection de Physiologie du travail et ergonomie, v. 73.

RABARDEL, P.; GOUÉDARD C. Pouvoir d'agir et capacités d'agir: une perspective méthodologique? Pistes, v. 14, n. 2, 2012.

ROSEMBERG, D. S.; RONCHI FILHO, J.; BARROS, M. E. B. de. (Org.). Trabalho docente e poder de agir: clínica da atividade, devires e análises. Vitória: EDUFES, 2011.

SANTORUM, K. et al. Análise coletiva da atividade de vigilância em saúde do trabalhador: a autoconfrontação cruzada como dispositivo de formação. Revista Reflexão $e$ Ação, Rio Grande do Sul, v. 16, n. 2, p. 77-96, 2008. Disponível em: $\quad<$ https://online.unisc.br/seer/index.php/reflex/article/ view/697/517>. Acesso em: 13 ago. 2015.

SCHWARTZ, Y. Um bref aperçu de l'histoire culturesse du concept d'activité. Activités, v. 4, n. 2, p. 122-133, 2007.

SCHWARTZ, Y.; DURRIVE, L. Trabalho e Ergologia. Niterói: EDUFF, 2010.

SILVA, C. O. Pesquisa e intervenção em clínica da atividade: a análise do trabalho em movimento. In: BENDASSOLLI, P. F.; SOBOLL, L. A. P. (Org.). Métodos de pesquisa e intervenção em psicologia do trabalho: clínicas do trabalho. São Paulo: Atlas, 2014. p. 81-99

SILVA, C. O.; SOUTO, A. P.; MEMÓRIA-LIMA, K. M. N. A pesquisa-intervenção em Psicologia do Trabalho em um aporte que toma o desenvolvimento como método e objeto. Fractal: Revista de Psicologia, Niterói, v. 27, n. 1, p. 12-15, abr. 2015. Cross ${ }^{\text {Ref. }}$
TEIGER, C.; LACOMBLEZ, M. L'ergonomie et la transformation du travail et/ou des personnes: permanences et évolutions (2. De 1980 à nos jours). Education Permanente, n. 166, p. 9-28, 2006.

VIGOTSKI, L. S. A formação social da mente (1925). São Paulo: Martins Fontes, 1998.

VIGOTSKI, L. S. Teoria e método em psicologia (1927). São Paulo: Martins Fontes, 1999.

VIGOTSKI, L. S. A construção do pensamento e da linguagem (1934). São Paulo: Martins Fontes, 2001.

Recebido em: 2 de junho de 2017 Aceito em: 17 de janeiro de 2018 